\title{
SALAS DE IMPRENSA EM SITES ORGANIZACIONAIS: ESTRATÉGIAS CONTEMPORÂNEAS DAS ASSESSORIAS DE COMUNICAÇÃO
}

\author{
PRESS ROOMS ORGANIZATIONAL WEBSITES: CONTEMPORARY STRATEGIES OF THE \\ PRESS OFFICE
}

\author{
SALAS DE PRENSA EN SITIOS WEB DE LA ORGANIZACIÓN: ESTRATEGIAS \\ CONTEMPORÁNEAS DE LA OFICINA DE PRENSA
}

\begin{abstract}
Daiana Stasiak
Professora do curso de Relações Públicas da Faculdade de Comunicação e Biblioteconomia (FACOMB) da Universidade Federal de Goiás (UFG). Relações Públicas e Mestre em Comunicação Midiática (UFSM); Doutoranda do Programa de Pós-Graduação em Comunicação da Universidade de Brasília (UNB). daiastasiak@gmail.com

\section{Laira Cristina Machado} Acadêmica do $3^{\circ}$ período do curso de Relações Públicas da Faculdade de Comunicação e Biblioteconomia da Universidade Federal de Goiás (UFG) laira_cm@hotmail.com
\end{abstract}

\section{Resumo}

A mídia tem papel fundamental para o reconhecimento das organizações no espaço público, porém, sabe-se que a transformação de fatos em notícias depende de alguns fatores conforme sinalizam hipóteses como "newsmaking". Nesse contexto, acredita-se que a consolidação da internet oferece possibilidades de transformação desse panorama, pois torna possível a disponibilização de informações independentes dos meios tradicionais ( $\mathrm{Tv}$, rádio e impressos), como ocorre, por exemplo, em sites organizacionais que passaram a empregar estratégias de comunicação e utilizar espaços denominados como "salas de imprensa" ou "media center" para valorizar acontecimentos organizacionais e chamar atenção dos jornalistas.

Palavras-chave: Relações Públicas, internet, newsmaking; visibilidade midiática.

\section{Abstract}

The media have a critical role for recognition of organizations in the public space, however, it is known that the transformation from facts in news depends on factors such as signal hypothesis newsmaking. In this context, it is believed that the consolidation of the internet offers possibilities to transform this landscape, it becomes possible to provide information 
independent of traditional media (TV, radio and print), as occurs, for instance, organizational Web sites began to use communication strategies and use spaces designated as "press rooms" or "media center" to enhance organizational events and draw attention from journalists.

Keywords: Public Relations, Internet, newsmaking; media visibility.

\section{Resumen}

Los medios de comunicación tienen un papel fundamental para el reconocimiento de las organizaciones en el espacio público, sin embargo, se sabe que la transformación de los hechos en las noticias depende de factores tales como la señal de hipótesis "newsmaking". En este contexto, se cree que la consolidación de la Internet ofrece posibilidades de transformar este paisaje, se hace posible para proporcionar información independiente de los medios de comunicación tradicionales (TV, radio y prensa escrita), como ocurre, por ejemplo, en sitios web de La organización que comenzaron a usar estrategias de comunicación y espacios de uso designado como "salas de prensa" o "media center" para mejorar los eventos de organización y llamar la atención de los periodistas.

Palabras clave: relaciones públicas, newsmaking; visibilidad mediática.

\section{INTRODUÇÃO}

O processo de midiatização da sociedade evidencia que na atualidade, ocorre um deslocamento da busca da legitimação institucional, pois, se antes era necessário que as organizações recorressem às mídias lineares para serem representadas e estarem visíveis, na sociedade atual organizações, atores sociais e mídia afetam-se continuamente.

Desse modo, parece-nos pertinente o estudo da apropriação das tecnologias digitais de comunicação pelas organizações com vistas a ampliar sua visibilidade diante dos públicos. Assim, planejar, executar e avaliar ações de comunicação institucional, práticas atribuídas às Relações Públicas, tornam-se mais complexas devido à midiatização das relações sociais e as novas formas de relacionamento proporcionadas pelas tecnologias digitais, que proporcionam mais espaços para a divulgação dos acontecimentos.

Em trabalhos anteriores, (STASIAK, 2009, 2010), discutimos as possibilidades da internet para a construção da visibilidade institucional diante dos públicos, o portal institucional, por exemplo, pode ser considerado um dispositivo no qual a instituição expõe-se com suas próprias palavras o que proporciona o acesso direto dos públicos às estruturas, valores e propósitos construídos ao longo da trajetória organizacional. 
O site organizacional é um tipo de espaço que abriga um grande número de estratégias de comunicação como, por exemplo: presença de pontos de identidade visual, agenda de eventos, publicações institucionais, espaços de fale conosco, ouvidoria, pesquisas e enquetes on-line, projetos institucionais, visita virtual, comunicação dirigida, uso de personagens virtuais, presença de canais de TV e Rádio on-line.

Além destas, é imprescindível o uso de estratégias como a presença de notícias institucionais, um local para informar os públicos onde são disponibilizadas notícias sobre a organização e assuntos afins. Além do clipping virtual que demonstra a visibilidade das ações organizacionais nos meios de comunicação tradicionais e o espaço para imprensa que apresenta releases e galeria de imagens com informações para o uso das mídias tradicionais e dos públicos. A partir destes pressupostos o artigo pretende demonstrar o potencial da internet para o uso de estratégias de comunicação com objetivo da obtenção da visibilidade das organizações nos meios de comunicação tradicionais (rádio, TV e impressos)

Para tanto se divide em três partes: a primeira aborda conceituações sobre o newsmaking, uma hipótese contemporânea da comunicação que busca a explicação de alguns fatores envolvidos na transformação dos acontecimentos em notícias nas mídias tradicionais, a segunda apresenta conceitos de Relações Públicas relacionados ao contexto da web com vistas a demonstrar que a interdependência entre estas áreas é fundamental no cenário da midiatização e a terceira traz a análise das seções "Media Center" e "Sala de Imprensa" das organizações Weg e Vale. Por fim, algumas considerações que apontam para a profissionalização de um espaço institucional no site bem como a proximidade entre veículos de comunicação tradicionais e espaços para a imprensa de sites organizacionais.

\section{HIPÓTESES CONTEMPORÂNEAS DA COMUNICAÇÃO: O NEWSMAKING}

Conforme Wolf (1995) o Newsmaking é uma hipótese da comunicação contemporânea ligada à sociologia do Jornalismo e considerada, por alguns estudiosos, uma “Teoria do Jornalismo", em sua tradução literal significa o 'fazedor da notícia'. Esta abordagem enfatiza a produção de informação, ou seja, a transformação dos acontecimentos em notícias e revela a existência de normas profissionais no processo de seleção das informações, uma das figuras abordadas é a do gatekeeper, denominado o 'guardião do portão', que se refere aos editores dos veículos midiáticos. 
O conceito de gatekeeper (seleccionador) foi elaborado por Kurt Lewin, num estudo de 1947 sobre as dinâmicas que agem no interior dos grupos sociais, em especial no que se refere aos problemas ligados à modificação dos hábitos alimentares[...] Lewin nota que existem neles zonas que podem funcionar como «cancela», como «porteiro»: Isso sucede não só com os canais de alimentação, mas também com a sequência de uma informação, dada através dos canais comunicativos, num grupo» (LEWIN, 1947, p. 145 apud WOLF, 1995, p.78).

Os processos de comunicação têm função de controle social estabelecido por práticas que ocorrem entre os profissionais de redação, neste caso a função do escolhedor seria influenciada por alguns pontos como: a autoridade institucional; o sentimento de fidelidade e estima com os superiores; as aspirações a mobilidade social do profissional; a ausência de fidelidade do grupo, caráter agradável do trabalho, a notícia ser transformada em valor.

Alguns pressupostos surgiram a partir de estudos feitos por White em 1950 que pesquisou o fluxo de informação num jornal dos EUA, na relação entre a chegada de notícias pelos telexes e a publicação na edição seguinte; a partir de 1333 releases recebidos concluiu que: 800 não foram publicadas por falta de espaço; 300 por falta de interesse do público, 200 por falta de qualidade do material enviado, 33 temas distantes dos leitores do jornal, ou seja, a cada 10 notícias enviadas à redação, apenas 1 era publicada.

A hipótese presume que existem algumas normas envolvidas na rotina diária da produção das notícias, tais normas geram uma distorção involuntária da informação, através da omissão constante ou ênfase permanente. $O$ conceito de noticiabilidade significa a aptidão potencial que um fato possui de se tornar uma notícia, o que conduz à afirmação de que as notícias são aquilo que os jornalistas definem como tal.

A noticiabilidade é constituída pelo conjunto de requisitos que se exigem dos acontecimentos - do ponto de vista da estrutura do trabalho nos órgãos de informação e do ponto de vista do profissionalismo dos jornalistas - para adquirirem a existência pública de notícias. Tudo o que não corresponde a esses requisitos é «excluído», por não ser adequado às rotinas produtivas e aos cânones da cultura profissional (WOLF, 1995, p.83).

Para tanto, estes tomam como referência os valores-notícia, um conjunto de qualidades dos acontecimentos que permitem uma construção narrativa e que os recomendam enquanto informação jornalística. Segundo Hohlfeldt (2001), essas qualidades são comumente agrupadas em cinco categorias: categorias substantivas (relativas ao fato em si), relativas ao 
produto ou notícia, relativas aos meios de informação, relativas ao público e relativas à concorrência. Apoiando-se nos conceitos de noticiabilidade e valores-notícia, o autor discorre também sobre as fases da produção de informação jornalística (captação, seleção, apresentação e distribuição), dando maior ênfase à fase de captação de informações.

$\mathrm{O}$ autor esclarece que o newsmaking exige a pesquisa participante, na qual os pesquisadores convivem com os pesquisados, a fim de observá-los profundamente. Assim como o agendamento, os estudos desta área sugerem a existência de uma espécie de hierarquia, um relacionamento permanente e alternativo entre os mais distintos meios de comunicação. Assim, tal hipótese pode comprovar que os processos de comunicação têm em si mesmos uma função de controle social. Desta maneira, Hohlfeldt conclui:

os meios de comunicação de massa devem tornar possível o reconhecimento de um fato desconhecido como algo notável de ser noticiado; elaborar relatos capazes de retirar do acontecimento seu nível de particularidade, tornando-o contextualizado; organizar temporal e espacialmente este conjunto de tarefas transformadoras, de modo que os eventos noticiados fluam e possam ser explorados racional e planificadamente. (HOHLFELDT, 2001, p. 207)

Através das definições apresentadas, observa-se que a perspectiva do newsmaking evidencia uma espécie de auto-suficiência do jornalismo, sugerindo que a comunicação se coloca em absoluta autonomia em relação às demais categorias sociais. Apesar deste equívoco, os estudos deste campo têm um papel de extrema importância na compreensão de como a informação flui entre fonte e jornalistas.

$\mathrm{O}$ advento da internet comercial muda, de certa forma o panorama dos fazedores de notícia, uma vez que são alteradas as formas de interação com o público-alvo, cada vez mais exigente e com maior poder de influenciar por ter ampliado os meios de acesso à informação.

As mudanças ocorrem em ritmo acelerado e de modo irreversível para as rotinas de produção, assim, existe a hipótese de que as organizações podem agir de forma estratégica em busca da noticiabilidade ao utilizar o site, por exemplo, como um espaço de valorização de suas ações de modo a atrair os jornalistas. Neste sentido, propõe-se que a área de Relações Públicas pode ser uma das responsáveis pelo processo de construção e manutenção dos conteúdos informacionais dos sites organizacionais com vistas à criação de valores-notícia para seus acontecimentos. 


\section{RELAÇÕES PÚBLICAS, INTERNET E SITES ORGANIZACIONAIS}

No contexto das novas mídias, é necessária a apresentação de informações essenciais para os públicos em sua tomada de decisão, quanto mais informados estiverem, maior será a possibilidade de que a instituição legitime-se. Da mesma forma a organização precisa preocupar-se também com espaços de relacionamento com os veículos de comunicação, para que estes entrem em contato com as ações desenvolvidas pela organização e as noticiem na busca da visibilidade.

A multiplicidade de acesso às informações amplia espaços de interação e traz novas configurações às práticas comunicacionais das organizações;

Nesse cenário, a gestão da comunicação nas organizações pautada no paradigma clássico/informacional, centrado na emissão e recepção de informações, torna-se insuficiente para administrar a abundância dos fluxos e demandas informacionais e a crescente rede de relacionamentos que se estabelece entre organização e atores sociais (OLIVEIRA e DE PAULA, 2007, p. 6).

É importante ressaltar que consideramos a busca da legitimidade como o princípio norteador da atividade de Relações Públicas, pois através desse processo as organizações e instituições conquistam a integralidade que colabora para sua permanência ao longo do tempo. Conforme Silva e Barichello:

o estabelecimento e a manutenção de relações, acontecimento possibilitado pela comunicação dirigida, é atualmente facilitado pelas redes digitais e Internet. Essas materialidades vão além das tradicionais matérias jornalísticas impressas, releases, malas-direta, folders, anúncios e campanhas publicitárias, chegam a interações, reciprocidades e apropriações, possibilitadas pelos suportes tecnológicos e digitais, nos quais os sujeitos destinatários são atuantes e determinantes da qualidade da comunicação, contribuindo para os processos de representação e reconhecimento da organização nos diferentes campos da sociedade contemporânea. (SILVA E BARICHELLO, 2006, p.10).

Para Kunsch (2003, p. 241) "pensar estrategicamente requer o conhecimento da organização e de suas condições, aspirações e aportes técnicos e tecnológicos para aplicá-las na prática e intervir no processo de planejamento e gestão estratégica". Acreditamos que 
realizar o diagnóstico da comunicação de uma instituição na atualidade implica, sobretudo, situar-nos diante das possibilidades midiáticas que estão à disposição.

Kunsch (2003) considera ainda que é mediante a sua função estratégica que as Relações Públicas abrem canais de comunicação em busca da confiança mútua e constroem a credibilidade. Porém, aponta que essa função está intrinsecamente ligada ao planejamento e à gestão estratégica e deve ser desenvolvida de forma sinérgica em conjunto com as outras áreas da comunicação.

Nessa perspectiva, o pensamento estratégico institucional configura-se como um composto que envolve conhecimento e criatividade ao promover uma perspectiva integrada dos acontecimentos sendo que, para sua efetivação, é necessário considerar o impacto da cultura da instituição, bem como as políticas internas e a formulação e implementação das estratégias.

Baldissera (2001) relata a importância da estratégia ser abordada como um critério para que o desempenho institucional seja superior e a comunicação firme-se como um fluxo e não apenas como um sistema que funciona em curto prazo. $\mathrm{O}$ autor considera que a internet condiciona uma mudança da mentalidade e do planejamento da instituição em relação às estratégias que irá adotar para seus públicos, principalmente pelo fator do rompimento das barreiras espaço-temporais, não presentes nas demais mídias.

Para Castells (1999) as modificações trazidas pelo advento da rede não ocorrem isoladamente, elas desenvolvem uma reação em cadeia que influencia todos os setores tanto de uma organização quanto de toda a sociedade.

O paradigma da tecnologia da informação é baseado na flexibilidade. Não apenas os processos são reversíveis, mas organizações e instituições podem ser modificadas, e até mesmo fundamentalmente alteradas, pela reorganização de seus componentes. (CASTELLS, 1999, p.108-109)

A reorganização pode gerar conseqüências como a prevalência de relacionamentos virtuais com os públicos, seja através do portal, blogs, comunidades virtuais, chats, fotologs. Essa constatação torna imprescindível que as organizações estejam preparadas para atuar neste novo cenário e utilizar os recursos disponíveis de uma forma estratégica. Para Bueno,

o relacionamento com os públicos de interesse deve pautar-se, agora, por agilidade e interatividade, e os comunicadores organizacionais devem ter a capacidade de estabelecer estratégias que levem em conta

ANIMUS R. Interamericana de Comunicação Midiática, http://www.ufsm.br/revistas E-ISSN 2175-4977, v. 10, n. 19, p. , 2011 
a potencialidade da Internet. As organizações ainda encontram dificuldades para se adaptar às novas mídias, com formatos e linguagens ainda insuficientemente explorados, mas, paulatinamente, vão descobrindo formas de conviver com elas (BUENO, 2003, p. 60).

Esse panorama trazido pelos desenvolvimentos sociotécnicos afeta as práticas profissionais, pois torna disponível novos espaços para o uso de ações estratégicas. Os portais organizacionais da internet são um dos principais expoentes de relacionamento com os públicos na contemporaneidade, conforme Pinho (2003a) o site é um dos canais ideais para esta disposição ilimitada de informações, pois firma-se como uma alternativa de comunicação midiática gerenciada pela própria organização.

\section{SALAS DE IMPRENSA EM SITES ORGANIZACIONAIS: ESTRATÉGIAS CONTEMPORÂNEAS DAS ASSESSORIAS DE COMUNICAÇÃO}

Para este artigo foram selecionados os sites de duas organizações brasileiras a primeira Weg Indústrias é uma empresa brasileira com sede em Jaraguá do Sul, Santa Catarina. Fundada em 1961, a partir da década de 1980 passou a fabricar geradores, componentes eletroeletrônicos, produtos para automação industrial, entre outros, é uma das únicas empresas brasileiras a aparecer na lista das 100 maiores pequenas empresas globais. ${ }^{1}$

A segunda Vale foi fundada em 1942, tornou-se, em 64 anos, a maior empresa de mineração diversificada das Américas. Em 2008, a Companhia Vale do Rio Doce deixou de usar a sigla CVRD, passando a usar o nome fantasia Vale e se tornou a $33^{\text {a }}$ maior empresa do mundo é a maior do Brasil em volume de exportações. A Vale é a segunda maior mineradora do mundo e a maior empresa privada do Brasil, maior produtora de minério de ferro do mundo e a segunda maior de níquel. ${ }^{2}$

O objetivo deste artigo visa relacionar as notícias institucionais publicadas no site de cada organização com as publicadas na imprensa tradicional e que obtém visibilidade através do próprio site organizacional, nas seções destinadas ao clipping. Para a realização deste objetivo foi realizada uma pesquisa qualitativa, de caráter exploratório-descritivo que considerou o conteúdo exposto no site das organizações como documentos organizacionais que configuraram recortes virtuais de determinados conteúdos de links específicos. No caso

\footnotetext{
${ }^{1}$ Disponível em http://pt.wikipedia.org/wiki/WEG_Ind\%C3\%BAstrias acesso em 10 out 2010.

${ }^{2}$ Disponível em http://pt.wikipedia.org/wiki/Vale_S.A. acesso em 10 out 2010.
} 
da organização Weg foram consideradas as seções "Media center" e "Weg na imprensa" e na Vale "Sala de imprensa" e "Vale na imprensa", além dessas seções outras foram adicionadas quando consideradas que possuíam informações relevantes para os objetivos da pesquisa.

A análise inicial foi realizada na seção "Media Center" do site da WEG que é composta por cinco menus sejam eles: notícias, Weg na imprensa, central de downloads, Weg em revista e boletim Weg. Ao clicar em "Notícias" o usuário é direcionado para a seção onde são apresentadas as notícias institucionais divididas em seções como, por exemplo: prêmios, resultados e investimentos, produtos e soluções, comunidade, corporativo, feiras e eventos e geral. As notícias recentes estão em destaque na coluna central enquanto as mais antigas estão no "arquivo de notícias" que possui filtros onde os públicos podem escolher o assunto por palavra-chave, data e seções por assunto.

A análise também foi focada na seção "Weg na imprensa" que apresenta as notícias relativas à organização que foram publicadas na mídia em geral, particularmente em jornais e revistas impressos e suas versões on-line, uma espécie de clipping da organização.

Esta seção apresenta uma coluna central com as publicações atualizadas diariamente bem como oferece a possibilidade de busca que pode ser realizada por palavra-chave e período. No final da seção são disponibilizados links com matérias publicadas por veículo, ou seja, ao selecionar um veículo o leitor será direcionado para uma página onde aparecem todas as notícias referentes à organização que foram publicadas naquele veículo.

No caso da organização Weg foram selecionadas doze (12) notícias institucionais publicadas no site entre os dias 25 de junho e 06 de outubro de 2010. Numa análise inicial realizou-se o mapeamento nas duas seções "Notícias" e "Weg na imprensa" a análise inicial demonstrou que as doze (12) notícias institucionais tiveram os mesmos assuntos publicados em 26 notícias da imprensa tradicional.

Dessas doze (12) notícias, cinco (5) estavam presentes na seção "corporativo" que apresenta notícias referentes a própria organização como, por exemplo, inovações da empresa, negociações de ações, programas de estágio, participação em semanas acadêmicas, ampliação, conquistas e incentivos aos diversos segmentos sociais, quatro (4) na seção "comunidade" com notícias sobre o apoio da empresa a ações culturais, históricas, de responsabilidade social, e três (3) na seção "produtos e soluções" que aborda notícias sobre novas tecnologias desenvolvidas nos produtos e sua utilização.

A análise específica de algumas notícias institucionais, listadas abaixo, demonstra que as matérias criadas pela organização e disponibilizadas em seu site possuem valores- 
notícia, capazes de gerar novas publicações como, por exemplo, a matéria, "Weg no ranking das mais inovadoras" que repercutiu em notícias veiculadas nos jornais "A Noticia" e na revista “Época Negócios”. Conforme segue:

Quadro 1: Notícia publicada no site da WEG. Link Corporativo. Data: 10 de setembro de 2010

\section{WEG no Ranking das mais inovadoras}

WEG conquista lugar entre as 20 companhias mais inovadoras do Brasil. O ranking encabeçado pela Whirlpool também contou com empresas como Vale, Embraco e White Martins

Tendo a Inovação como uma das prioridades ao longo de sua trajetória, a WEG recebeu no dia 9 de Setembro, em São Paulo, o prêmio Empresas mais Inovadoras do Brasil 2010. Promovido pela Revista Época Negócios em parceria da consultoria da A.T Kearney, a premiação contemplou as 20 empresas que compõem o ranking da inovação, analisadas por 12 mil consumidores do país e selecionadas entre as 120 companhias inscritas.

A lista, encabeçada pela Whirlpool, contou também com empresas como Embraco, O Boticário, Vale e White Martins. A WEG, que possuí hoje $75 \%$ de seu faturamento originado de produtos lançados nos últimos três anos, ficou com a 19a colocação."A inovação é uma questão de sobrevivência para nós", afirma Milton Castella, Diretor de Engenharia da WEG. "Nossos diferenciais são essenciais, já que os motores começam a se tornar commodities no mercado internacional", completa.

Na seção que apresenta a matéria publicada na mídia, a assessoria disponibiliza dados como o nome dos veículos, a seção no qual foi publicada, a localidade, a data e o horário (no caso de jornais on-line). Conforme ilustrado a seguir.

Quadro 2: Notícia veiculada no Jornal 'A Notícia' de Joinville/SC. Edição Impressa. Data: 16 de setembro de 2010.

\section{A NOTÍCIA \\ Prêmio empresarial}

A WEG recebeu o prêmio Empresas mais Inovadoras do Brasil 2010, da revista “Época Negócio". Vinte empresas que mais investiram em inovação foram escolhidas entre as 120 inscritas. A WEG, que tem hoje $75 \%$ de seu faturamento com produtos lançados nos últimos três anos, ficou com a $19^{\mathrm{a}}$ colocação. 
Quadro 3: Notícia veiculada no site Época Negócios. Seção. Notícias. São Paulo. 10 de setembro de 2010. 8 h16min

\section{Para a WEG, a inovação é uma questão de sobrevivência por Elisa Campos}

Cerca de $75 \%$ do faturamento da fabricante de motores é originado de produtos lançados nos últimos três anos Milton Castella, diretor de engenharia da WEG, e Eduardo Leite, diretor de publicidade da Editora Globo Inovar é uma das prioridades da fabricante catarinense de motores elétricos WEG. "A inovação é uma questão de sobrevivência para nós", afirma Milton Castella, diretor de engenharia da empresa. Com $75 \%$ de seu faturamento originado de produtos lançados nos últimos três anos, a companhia ficou na $19^{a}$ colocação no prêmio As Empresas Mais Inovadoras do Brasil, uma iniciativa de Época NEGÓCIOS ...

Esta notícia serviu como ilustração das demais, um dado relevante percebido na pesquisa é referente às datas de publicação, somente uma (1) notícia, entre as doze (12), foi publicada primeiro na mídia e depois no site organizacional, "Maior refinaria da Petrobrás conta com tintas Weg" que foi publicada na Revista "TN Petróleo" do Rio de Janeiro, as demais foram noticiadas primeiramente no site e depois nos demais meios de comunicação.

No caso da empresa WEG podemos concluir que o espaço de notícias do site pode servir como um dos alimentadores das mídias tradicionais, a iniciativa de disponibilizar o clipping em forma virtual pode ser considerado como um agregador de valor para a organização pois demonstra que ela transforma dados em notícias e os disponibiliza de modo organizado e atualizado o que pode ser um fator que contribui para que os jornalistas insiram as matérias em suas pautas e publiquem em seus veículos.

A segunda empresa analisada, conforme descrito acima é a Vale, seu site possui o link "Sala de Imprensa" localizado no menu superior, ao clicar encontra-se a seguinte definição "Na sala de imprensa on-line Vale, você encontra os nossos últimos releases, além de informações, notícias, áudios e vídeos atualizados em tempo real" a seção parece ser mais interativa do que a outra organização, o menu "Últimas notícias", na parte esquerda superior apresenta as notícias da organização, logo abaixo estão as seções "TV Vale" e "Rádio Vale" que disponibilizam as matérias em áudio e vídeo que foram veiculadas sobre a organização.

Já a seção "Releases" apresentam-se notícias institucionais de todos os setores da organização. Na parte direita está disponível o sistema de buscas onde se podem encontrar 
notícias por categoria como: corporativo, cultura, empresas do grupo, energia, informações financeiras, logística, entre outros. É importante ressaltar que existem notícias institucionais em seções denominadas "Destaques" nos links "Conheça a Vale", "O que fazemos" e "Sustentabilidade". A parte inferior do site possui ainda uma seção de "Tags" que apresenta uma série de palavras referentes à sala de imprensa que servem como um atalho de acesso às expressões mais lidas.

No caso do site da Vale foram analisadas as seções "Releases" e "Destaques" para mapear as notícias institucionais e a seção "Vale na Imprensa" que possui notícias sobre a organização veiculadas nas mídias. No total foram treze (13) notícias institucionais, publicadas entre os dias 15 de abril e 4 de outubro de 2010, dentre elas oito (8) localizadas na seção releases, três (3) na seção "corporativo", três (3) em "fatos relevantes/oficiais" uma (1) na seção "meio ambiente" e uma (1) na seção "investimentos sociais", as demais se encontram nas seções "Destaque" duas (2) no link "Conheça a Vale", uma (1) no link "Sustentabilidade" e uma (1) no link "O que fazemos" e outra do link "Carreiras", estas geraram 23 notícias na mídia.

Dentre algumas podemos destacar a notícia "Vale conclui aquisição de ativos da Bunge e Fosfértil" que teve repercussão nos veículos "Isto É Dinheiro" e "DCI". Outra notícia "Investimento será de 400 milhões" publicada na seção de Releases e também da "Sustentabilidade" virou notícia nos jornais Folha de São Paulo "Vale pretende criar MIT brasileiro" e também no Brasil Econômico "Vale investe em parte tecnológica".

A notícia "São 1.200 vagas para estudantes" publicada no site teve repercussão nos veículos “A Tarde” do Maranhão e "Estado de Minas”. Já a notícia "Relatório de sustentabilidade é premiado" publicado na seção meio ambiente foi notícia no Jornal o Globo com o título "Carbono Controlado"

Quadro 4: Notícia publicada no Site da Vale. Data: 4 de outubro de 2010

\section{São 1.200 vagas para estudantes}

Estão abertas as inscrições para o Programa de Estágio da Vale. São 1.200 vagas para estudantes do ensino técnico e superior, dos estados do Rio de Janeiro, São Paulo, Goiás, Minas Gerais, Bahia, Sergipe, Pará e Maranhão. As inscrições podem ser feitas até 19 de outubro. Há vagas para mais de 40 cursos de diferentes áreas para estudantes do ensino técnico e superior. O valor da bolsa-auxílio, a partir de $\mathrm{R} \$ 400$, irá variar de acordo com a carga horária e o grau de escolaridade. Outros benefícios como assistência médica, seguro de vida, vale refeição e transporte também são oferecidos. 
Quadro 5: Notícia Publicada no Jornal “A Tarde”do Maranhão. Data: 5 de outubro de 2010

II MERCADO DE TRABALHO

Grandes empresas, como Vale, Ferrovia Centro-Atlantica

Usiminas e Braskem, abrem seleçao para 1,3 milvagas

Hora boa para fazer estágio
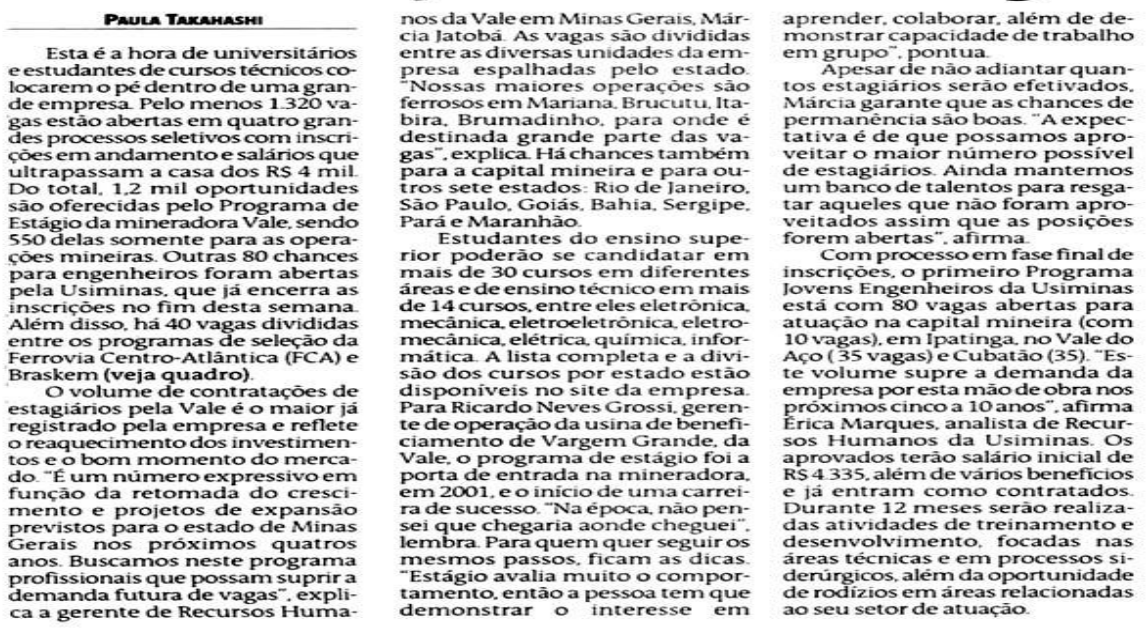

Quadro 6: Notícia publicada no Jornal "Estado de Minas", Minas Gerais. Data: 5 de outubro de 2010

\section{Vale abre 1,2 mil vagas de estágio}

A Vale abriu inscrições para 1,2 mil vagas de estágio para estudantes do ensino técnico e superior, dos estados do Rio de Janeiro, São Paulo, Goiás, Minas Gerais, Bahia, Sergipe, Pará e Maranhão.

As inscrições podem ser feitas pelo site www.vale.com/oportunidades até o dia 19 de outubro.

Para os estudantes de ensino superior serão oferecidas vagas em mais de 30 cursos em diferentes áreas, como engenharia, geologia, administração, arquitetura, química, direito, informática, comunicação, psicologia, ciências contábeis, ciências biológicas, comércio exterior, entre outras. A lista completa e a divisão de cursos, por estado, estão disponíveis no site.

Estudantes de ensino técnico terão a oportunidade de se inscrever também em mais de 14 cursos, entre eles eletrônica, mecânica, eletroeletrônica, eletromecânica, elétrica, química, informática, administração, meio ambiente, secretariado, administração e enfermagem.

Os selecionados iniciarão o estágio de janeiro até março de 2011 e receberão bolsa-auxílio mensal de R\$400 a R\$ 900 (os valores variam dependendo do curso, técnico ou superior, e da carga horária), assistência médica e seguro de vida.
Nas unidades onde a empresa não oferece transporte e restaurante, os estagiários também receberão vale-transporte e vale-refeição. A carga horária do estágio varia de 4 e 6 horas, dependendo da função.

Para participar do processo seletivo, os estudantes de ensino superior devem estar em período equivalente a dois anos para concluir o curso, ter conhecimentos de inglês e de informática.

Para os candidatos de ensino técnico, a exigência é que estejam a um ano de concluir o curso ou sejam recémformados que ainda não tenham cumprido a carga horária de estágio obrigatório. 
Com relação a empresa Vale a pesquisa permitiu apontar que a seção sala de imprensa pode ser considerada mais completa em relação a mesma da empresa Weg, assim como a divisão de assuntos e pautas tem mais referências e assuntos do que a outra organização, a presença de informações em áudio e vídeo também podem ser indicativos de pautas para meios de comunicação como rádio e TV, a apresentação do clipping com os recortes próprios do veículo ainda podem indicar mais credibilidade ao leitor, pois apresenta a página do jornal, como foi o caso, assim como ela é publicada no modo impresso. De modo geral as datas apresentadas na sala de imprensa e na seção de clipping nos levam a perceber que a Vale gera pautas para os diversos veículos.

\section{CONSIDERAÇÕES FINAIS}

As referências bibliográficas e a análise empírica nos levam a compreender que se configura um novo espaço de interação entre os jornalistas das mídias tradicionais e as assessorias de comunicação das organizações. Tanto o layout quanto os materiais dos locais denominados "Media Center" no caso da empresa WEG e "Sala de imprensa" no caso da Vale, nos permitem afirmar que as organizações utilizam de forma proveitosa seus sites para a busca de relacionamento com a mídia.

A análise das matérias permite-nos entender a existência da conexão dos jornalistas com os espaços dedicados a imprensa nos sites, um dos fatores que colabora para isso é a relação com as datas, a maioria das matérias que aparecem nas seções de clipping são publicadas primeiro no site e tem como base os seus conteúdos. Por isso, é importante que se realizem reflexões teóricas sobre as mudanças nas rotinas de produção, principalmente devido ao advento da internet e a proliferação de publicações on-line, que podem interferir nas questões da escolha de publicações pelos jornalistas e também em fatores como o deadline das matérias, por exemplo.

Assim, é imprescindível que as organizações mantenham seus sites atualizados para poderem colaborar com pautas constantemente. Nesta pesquisa inicial confirmamos a hipótese de que as organizações utilizam seus portais de forma estratégica, pois valorizam as ações da organização diante dos jornalistas bem como geram valores-notícia de assuntos organizacionais que, se não estivessem publicados na rede poderiam não ser aproveitados em sua totalidade.

Conforme ilustra a hipótese do newsmaking, existem inúmeros fatores que colaboram para a publicação, ou não, de um conteúdo nos veículos das mídias tradicionais, esta pesquisa 
nos leva a pensar em mais um item para esta listagem, a presença das notícias na internet que podem ser utilizadas como fonte de informação para jornalistas, por isso, acredita-se que a presença e manutenção da comunicação organizacional on-line é primordial para as empresas na contemporaneidade bem como a contribuição teórica que deriva da análise, interpretação e re-interpretação de conceitos e teorias da área a partir das transformações midiáticas que ocorrem no cotidiano dos profissionais da comunicação.

\section{REFERÊNCIAS}

BALDISSERA, Rudimar. Estratégia, comunicação e Relações Públicas. In: CONGRESSO BRASILEIRO DE CIÊNCIAS DA COMUNICAÇÃO, 24, 2001. Campo Grande, MS. Anais...Campo Grande: UFMS.

BUENO, Wilson da Costa (2003). Comunicação empresarial: teoria e pesquisa. São Paulo: Manole.

CASTELLS, Manuel. A sociedade em rede. São Paulo: Paz e Terra, 1999.

HOHLFELDT, A. MARTINO L. e FRANÇA V. (orgs) Teorias da comunicação: conceitos, escolas e tendências. Petrópolis: Vozes, 2001.

KUNSCH, Margarida M. Krohling. Planejamento em Relações Públicas na Comunicação Integrada. $4^{\mathrm{a}}$ ed, São Paulo: Summus, 2003.

OLIVEIRA, I. L.; PAULA, C. F. C. de (2006).Comunicação organizacional: processo de interlocução entre organização e interlocutores. In: PINTO, J.; SORELLE, M. (orgs) Interações Midiáticas. Belo Horizonte: Autêntica.

PINHO, J. B (2003). Relações Públicas na Internet: técnicas e estratégias para informar e influenciar públicos de interesse. São Paulo: Summus.

SILVA, J.Q. e BARICHELLO, E.M.R. A representação das organizações no espaço midiatizado. In: CONGRESSO BRASILEIRO DE CIÊNCIAS DA COMUNICAÇÃO, 29, 2006. Brasília, DF. Anais....Brasília, UNB.

STASIAK, Daiana. Estratégias comunicacionais e práticas de WebRP: o processo de legitimação na sociedade midiatizada. Santa Maria 229p. Dissertação de Mestrado - Programa de Pós-Graduação em Comunicação Midiática, Universidade Federal de Santa Maria, 2009.

STASIAK, Daiana. As Relações Públicas sob novos olhares teóricos. In: CONGRESSO BRASILEIRO DE CIÊNCIAS DA COMUNICAÇÃO, 33, 2010. Caxias do Sul, RS. Anais....Caxias do Sul, UCS.

WOLF, Mauro. Teorias da Comunicação. Presença. Lisboa, 1995. 
Original recebido em: 11/04/2011

Aceito para publicação em: 12/09/11

Resumo dos autores:

${ }^{1}$ Daiana Stasiak é professora Assistente do Curso de Relações Públicas da Universidade Federal de Goiás (UFG). Doutoranda do Programa de Pós Graduação em Comunicação da Universidade de Brasília (UNB) na linha de Pesquisa Teorias e Tecnologias da Comunicação. Mestre em Comunicação pelo Programa de PósGraduação em Comunicação Midiática da Universidade Federal de Santa Maria (UFSM), bolsista da Coordenação de Aperfeiçoamento de Pessoal de Nível Superior (CAPES), graduada em Relações Públicas pela mesma Universidade. Desempenhou projetos de pesquisa e extensão e trabalhou com planejamento, execução e avaliação de atividades da Assessoria de Comunicação na Seção Sindical dos Docentes da UFSM (SEDUFSM) e na Câmara Municipal de Vereadores de Santa Maria (CMVSM). É pesquisadora do grupo de Pesquisa de Comunicação Institucional e Organizacional (UFSM/CNPq) e líder do grupo WEBRP - Práticas de Relações Públicas em Suportes Midiáticos Digitais (UFSM/CNPq) e realiza pesquisa sobre as temáticas: midiatização, campo dos media, legitimidade institucional, Relações Públicas na internet (WebRP), estratégias de comunicação.

http://buscatextual.cnpq.br/buscatextual/visualizacv.do?id=K4227492E6

\section{${ }^{2}$ Laira Cristina Machado}

É Acadêmica do $3^{\circ}$ período do curso de Relações Públicas da Faculdade de Comunicação e Biblioteconomia da Universidade Federal de Goiás (UFG)

http://buscatextual.cnpq.br/buscatextual/visualizacv.do?id=K4498592T7 